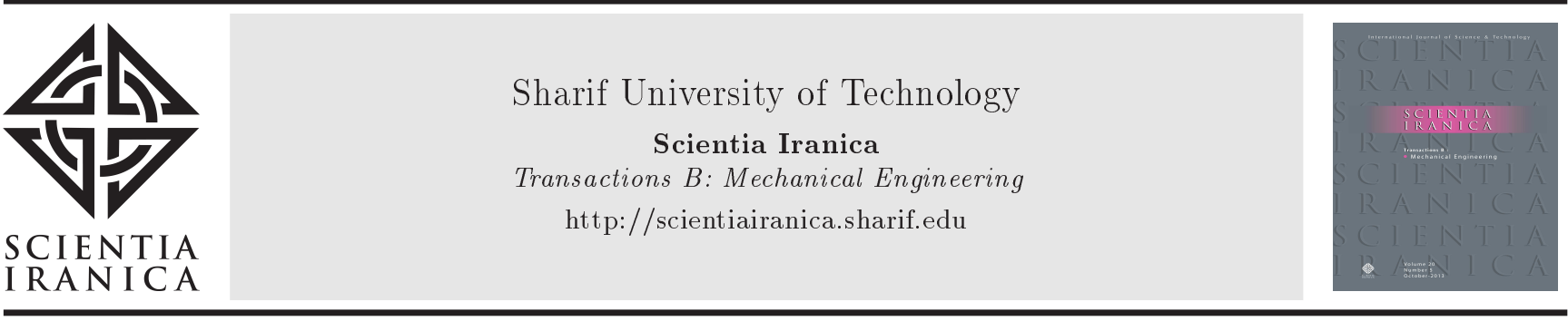

\title{
Investigating the effects of impact directions on improving head injury index
}

\author{
J. Afshari ${ }^{a, *}$, M. Haghpanahi ${ }^{a}$, R. Kalantarinejad ${ }^{\mathrm{b}}$, and A. Rouboa ${ }^{\mathrm{c}}$ \\ a. School of Mechanical Engineering, Iran University of Science and Technology, Tehran 16846-13114, Iran. \\ b. Iranian Ministry of Science and Research Technology, Aerospace Research Institute, Tehran, 14657-74111, Iran. \\ c. CIENER-INEGI polo UTAD, University of Trás-os-Montes e Alto Douro, 5001-801Vila Real, Portugal.
}

Received 17 September 2017; received in revised form 26 December 2018; accepted 6 April 2019

\section{KEYWORDS}

Brain injury;

Computational modeling;

Finite element

method;

Injury criteria;

Safety.

\begin{abstract}
Traumatic Brain Injury (TBI) is one of the most important causes of death and disability. The objective of this study was to develop new Head Injury Criteria (HIC), which could predict the Maximum Principal Strain (MPS) and shear stress in the brain considering the impact directions and magnitudes. Accordingly, 150 head impact simulations were performed with three magnitudes and 50 directions of impact using head Finite Element Model (FEM). Simulations were performed in order to assess the strain and shear stress in the brain tissues due to different impact directions and magnitudes. Next, new HIC were developed through performing statistical analysis. The simulation results showed that TBI risks in the sagittal and frontal planes were higher than those in transverse plane. Furthermore, new brain injury indices were developed to predict MPS and shear stress in the brain, which had correlation coefficients of 0.85 and 0.89 with the head FEM responses, respectively. The findings of the present research showed the effects of impact directions on TBI risks. They also demonstrated that impact magnitude, direction, and duration should be used to develop a brain injury index.

(C) 2020 Sharif University of Technology. All rights reserved.
\end{abstract}

\section{Introduction}

Traumatic Brain Injury (TBI) is one of the most important causes of death and disability. TBIs often decrease the ability of a person to function and interact socially [1]. Almost 1.7 million cases of TBI per year are reported in the United States [2]. Also, about 170000 TBI events occur in Canada every year, of which the elderly and children are the frequent victims [3]. These injuries decrease ability and productivity of those who

*. Corresponding author. Tel.: +98 8138338287; Fax: +982173021585

E-mail addresses: j_afshari_m@yahoo.com (J. Afshari); mhaghpanahi@iust.ac.ir (M.Haghpanahi); rezakalantarinezhad@gmail.com (R. Kalantarinejad); rouboa@seas.upenn.edu (A.Rouboa)

doi: $10.24200 /$ sci. 2019.5202 .1148 are not able to work. The medical TBI reports are generally underestimated, because almost $25 \%$ of all mild and moderate cases are not included and many concussions do not come under clinical attention. The most frequent cause of TBI is falls, followed by vehicle events and striking accidents in which a person is hit by an object. TBIs may also occur during military events, vehicle crashes, and sports events $[1,4-8]$. This study aims to better understand the head injury mechanisms.

Various studies have been performed on brain injury to decrease TBI risk. This is facilitated by understanding those factors that play an important role in such injuries, including what characteristics an event should have in order to cause a head injury [9-12]. Head responses during impacts have been measured using helmet-mounted accelerometers [13,14]. Moreover, determination of the types of head impacts that cause such injuries 
can be one of the main areas of research [15-17]. Any types of TBI can be evaluated based on the events by identifying the effects of certain impacts and directions on TBIs. Furthermore, this knowledge will help designers and engineers make new protective devices and safer equipment to decrease TBI risk.

Most of the injury criteria based on head kinetics are obtained from experimental results. They have become a basis for many head injury protocols, including vehicle safety standards and helmet design standards [18-22]. Head Injury Criteria (HIC) [18] and Gadd Severity Index (GSI) [19] are employed to predict TBI risk based on weighted integrals of translational acceleration time during impacts. On the other hand, Brain Injury Criterion (BRIC) evaluates head injury using head rotational kinematics [20]. Rowson proposed injury risk curves for TBI based on translational and rotational impacts for injury events among collegiate athletes [23]. These HIC are usually calculated to assess TBI risk by using impact time and magnitude without considering the impact orientation. Therefore, they do not show any differences between input impacts with different directions and identical profiles for TBI risk. However, some researchers have proved that impact directions should be considered in predicting TBI risk, because human head is composed of geometries with varying material properties [24-27].

Research done on cadavers and test animals has shown the effects of impact direction on the TBI risk [28]. The use of animal studies for human subjects has many limitations. Coronal impact effects on the brain reactions were investigated by Gennarelli et al. [25], who also assessed the effects of sagittal plane impacts on the brain injury. Also, some research has been done by Kleiven [29] and Huang et al. [30] to identify the effect of impact direction on TBI risk by using Finite Element Model (FEM) simulations of the sagittal plane. Although some studies have shown the effects of impact orientation, few studies have addressed the effect of impact direction on human brain injury considering human anatomical aspects.

Finite element simulations have been conducted to study the relationship between head kinetics and TBIs. Also, investigation into the brain reactions and prediction of TBI risk have been carried out using head FEMs in soccer events, motor vehicle crashes, falls, and other impact scenarios [20,31-33]. Brain stress and strain responses in FEM are very useful tools to study TBI risk [34-39]. Although FEM is helpful in studying TBI risk by taking impact direction into consideration, it is time-consuming. Therefore, kinematics-based HIC, like head FEMs, should be proposed to prevent head injury and predict brain stress as well as stress responses.

In this study, the relationship between brain reactions and head kinematics is evaluated using a
3D human head FEM in different anatomical planes. The relationship of impact directions and acceleration magnitudes to TBI risk based on Maximum Principal Strain (MPS) and shear stress is investigated using 150 finite element head impact simulations. Finally, statistical analysis will be performed to propose MPS and shear stress criteria for predicting brain reactions.

\section{Method}

\subsection{Head Finite Element Model (FEM)}

Horgan and Gilchrist's head model was employed to create the head FEM. Their initial head FEM involved brain, specific subarachnoid for Cerebro-Spinal Fluid (CSF), tentorium cerebral, falx cerebri, skull, and face. Also, skull, facial bone, CSF, dura mater, pia mater, and combined properties of the grey and white matter of the brain were modeled in it using brick, shell, brick, shell, membrane, and brick elements, respectively $[27,40]$. In this study, different anatomic layers were applied to the original model to improve its accuracy in modeling the head layers. The improved model had scalp, three-layer skull including cortical and spongy bone, dura mater, trabeculae and CSF under subarachnoid, pia mater, tentorium cerebral, falx cerebri, brain, and face [26].

Our model consisted of 27031 elements including 7107 shell elements and 19924 hexahedral elements. An illustration of the improved FEM is given in Figure 1. Detailed mechanical properties of all the components of this head model are illustrated in Table 1.

Cortical and spongy bone, dura mater, arachnoid, and pia mater were defined in ABAQUS (a commercial software package for finite element analysis developed by Dassault Systems and applicable to various disciplines of engineering) by Prony series to control large deformations [27]. Other parts of the model were considered linear elastic. For the viscoelastic section, the relaxation shear modulus $G_{R}(t)$ was introduced in ABAQUS software by dimensionless function $g_{r}(t)$ expressed by Prony series in Eq. (1). Zhou work group [41] developed this equation:

$$
g_{r}(t)=1-\sum_{i=1}^{N} G_{i}\left[1-\exp \left(-t / \tau_{i}\right]\right.
$$

where $G_{0}$ is the instantaneous shear modulus, $g_{r}(t)=$ $\left(G_{R}(t)\right) / G_{0}$, and $\tau_{i}$ is stress relaxation time. When time $t$ takes an infinite value, long-time shear modulus is calculated through Eq. (2) [26]:

$$
G_{\infty}=G_{R}(\infty)=g_{R}(\infty) \times G_{0} .
$$

The improved model was validated by the results of two research works by Nahum, including impact along the mass center of the head, and Trosseille, 

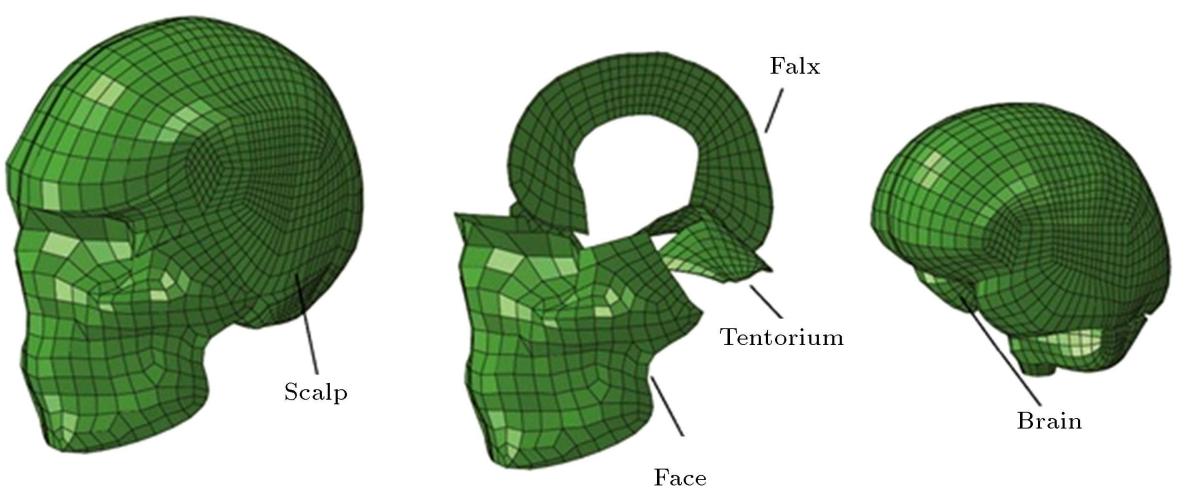

Figure 1. Developed head finite element model [27].

Table 1. Mechanical properties of the components of the head finite element model [27].

\begin{tabular}{|c|c|c|c|c|c|c|c|}
\hline Layer & Behavior & $\begin{array}{c}\text { Thickness } \\
\text { ( } \mathrm{mm})\end{array}$ & $\begin{array}{l}\text { Density } \\
\left(\mathrm{kg} / \mathrm{m}^{3}\right)\end{array}$ & $\begin{array}{l}\text { Long-term } \\
\text { elastic } \\
\text { modulus } \\
(\mathrm{MPa})\end{array}$ & $\begin{array}{l}\text { Bulk } \\
\text { modulus } \\
(\mathrm{MPa})\end{array}$ & $\begin{array}{l}\text { Poisson's } \\
\text { ratio }\end{array}$ & $\begin{array}{l}\text { Viscoelastic } \\
\text { response } \\
\quad\left(g_{R}(t)\right)\end{array}$ \\
\hline Skin & Elastic & 5 & 1130 & 16.7 & 35 & 0.42 & - \\
\hline Cortical bone & Viscoelastic & 4 & 2000 & 13000 & 8929 & 0.22 & $\begin{array}{l}1-0.0293\left(1-e^{-t / 9}\right) \\
-0.0656\left(1-e^{-t / 950}\right) \\
-0.0278\left(1-e^{-t / 9500}\right) \\
-0.107\left(1-e^{-t / 90.000}\right)\end{array}$ \\
\hline Trabecular bone & Viscoelastic & 2 & 1300 & 888 & 740 & 0.3 & $\begin{array}{l}1 \\
-0.6224\left(1-e^{-t / 711.23}\right) \\
-0.2143\left(1-e^{-t / 4267.4}\right)\end{array}$ \\
\hline Dura mater & Viscoelastic & 0.4 & 1140 & 11.72 & 7 & 0.23 & $\begin{array}{c}1-0.1088\left(1-e^{-t / 40}\right) \\
-0.0959\left(1-e^{10.00}\right) \\
-0.0922\left(1-e^{-t / 1000.00}\right)\end{array}$ \\
\hline Arachnoid mater & Viscoelastic & 0.35 & 1130 & 19.32 & 64 & 0.45 & $1-0.919\left(1-e^{-t / 0.002}\right)$ \\
\hline CSF & Elastic & 0.15 & 1000 & 0.015 & 2273 & 0.499989 & - \\
\hline Pia mater & Viscoelastic & 0.15 & 1130 & 19.32 & 64 & 0.45 & $1-0.919\left(1-e^{-t / 0.002}\right)$ \\
\hline Trabeculae & Elastic & 1.5 & 1130 & 0.050 & 22 & 0.48 & - \\
\hline Brain & Viscoelastic & - & 1040 & 0.0228 & 2278 & 0.49998 & $1-0.815\left(1-e^{-t / 0.0143}\right)$ \\
\hline
\end{tabular}

including off-center impact in order to validate brain reactions. Six samples of Nahum test (1977) were utilized to validate pressure prediction in the head FEM [42]. Moreover, the Trosseille MS 428_2 test (1992) was used to validate brain response with the cadaver in a seated position. It was impacted by a $23.4 \mathrm{~kg}$ hammer with the velocity of $7 \mathrm{~m} / \mathrm{s}$ in the anterior posterior direction $[27,43]$.

\subsection{Injury criteria for Traumatic Brain Injury (TBI)}

The injury criteria for TBI were divided into those related to the motion of the whole head (macro scale) and those related to the deformation of tissues within the head (tissue level). The macro-scale criteria are being measured in experimental studies. Therefore, they have become a basis for numerous head injury 
events. Tissue-level thresholds are measured using FEMs [22].

HIC are among the most important macro-scale injury criteria first improved and advanced upon SI (Severity Index) by Versace (1971) [18], which is the current index for head injury used in the FMVSS 208 standard. The HIC equation is defined as follows:

$$
H I C=\max \left(\left(t_{2}-t_{1}\right)\left(\frac{1}{t_{2}-t_{1}} \int_{t_{1}}^{t_{2}} a(t) d t\right)^{2.5}\right)
$$

where $a(t)$ is the resultant linear acceleration at the head center of gravity. Also, $t_{1}$ and $t_{2}$ are the initial and final times, respectively, by which $\mathrm{HIC}$ are calculated $\left(t_{1}\right.$ and $t_{2}$ are selected to maximize HIC). The HIC values should be below 1000 to prevent serious brain injury [18].

Several tissue-level injury criteria have been proposed to predict injury in brain FEMs. Most of these criteria have been investigated by reconstructing reallife accidents such as falls, hockey collisions, pedestrian accidents, soccer events, vehicle accidents, and crashes using anthropomorphic test devices and head FEMs. The developed injury criteria usually use stress and strain values. Although head FEMs have different anatomical structures with different injury criteria, the same value for brain injury tolerances has been proposed to predict TBI risk [27]. Head tissue injury criteria of MPS and shear stress were used to investigate head trauma in this study. They were selected based on the previous research on determining brain injuries [44-47]. The proposed tolerance limits for the risk of head trauma are about $7.5 \mathrm{kPa}$ (Kilo Pascal) and 0.25 for shear stress and MPS, respectively.

\subsection{Computational simulations}

This study was performed using a head FEM with multiple anatomic parts and various material properties, which were validated by the results of the previous experimental data. Simulations were carried out in ABAQUS software using the dynamic explicit method. They were performed with three different magnitude impact pulses applying about 50 different directions of impact, resulting in 150 simulations (Tables 2 and 3 ). Using a cube as an example, translational impacts were applied to each of the following 50 vectors: 8 vectors

Table 2. Head Injury Criteria (HIC) values and the peaks of linear input impacts.

\begin{tabular}{ccc}
\hline Input & $\begin{array}{c}\text { Peak of linear } \\
\text { acceleration }\left(\mathbf{m} / \mathbf{s}^{2}\right)\end{array}$ & HIC value \\
\hline R1 & 2000 & 1960 \\
R2 & 1500 & 956.7 \\
R3 & 1200 & 547.7 \\
\hline
\end{tabular}

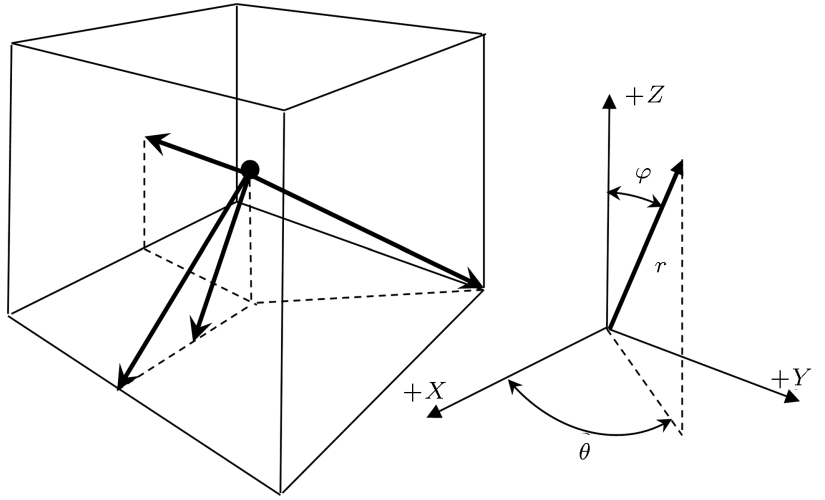

Figure 2. Directions of the input impacts showing the spherical coordinate system.

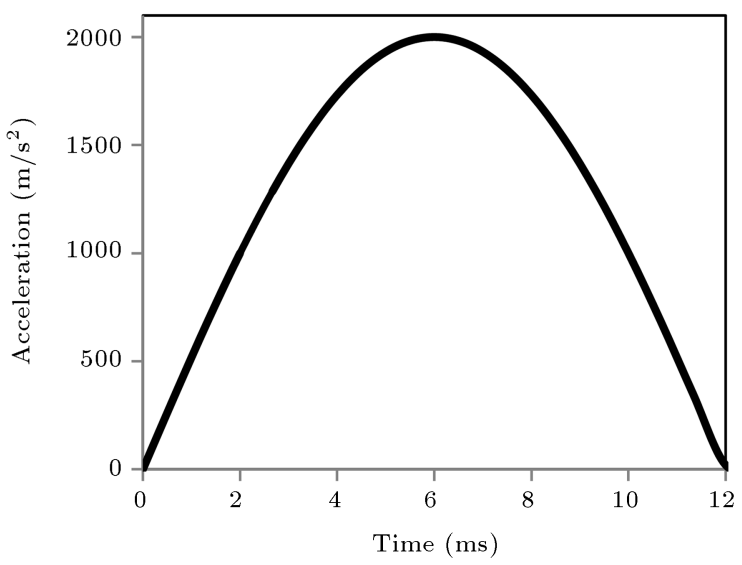

Figure 3. Kinematic input shape for translational accelerations.

from the center to the middle of each cube face, 8 vectors from the center to the cube corners, 12 vectors from the center to the midpoint of each cube edge, and 24 vectors from the center to the middle of the space between the middle of each cube face and each cube edge (Figure 2 and Table 3) [27]. The spherical coordinate system $(r, \theta, \varphi)$ was used to describe the impact orientations, as illustrated in Figure 2, where $Z$ and $X$ axes were aligned with superior and anterior directions in the head, respectively. Translational accelerations were applied to the head center of gravity as loading conditions on the skull were assumed rigid. The input load to the head FEM was an acceleration [27,42], as shown in Figure 3, which was applied with different magnitudes and directions. The model was not allowed to have rotation in order to isolate the effects of translational direction and magnitude on the response of the brain model.

\subsection{Post-processing of simulations}

Effects of orientation and peak linear impact on the brain responses (including principal strain and shear stress) were evaluated. Seventeen pairs of impact directions were symmetric relative to the head FEM 
Table 3. Unit vectors of applied impact directions [27].

\begin{tabular}{|c|c|c|c|c|c|c|c|}
\hline Run & Anatomical direction & Direction & $\phi$ & $\theta$ & $\boldsymbol{x}$ & $y$ & $z$ \\
\hline 1 & Anterior & $\mathrm{x}$ & 90 & 0 & 1 & 0 & 0 \\
\hline 2 & Posterior & $\mathrm{x}(-)$ & 90 & 180 & -1 & 0 & 0 \\
\hline 3 & Left & $\mathrm{y}$ & 90 & 90 & 0 & 1 & 0 \\
\hline $3^{*}$ & Right & $\mathrm{y}(-)$ & 90 & -90 & 0 & -1 & 0 \\
\hline 4 & Superior & $\mathrm{z}$ & 0 & 0 & 0 & 0 & 1 \\
\hline 5 & Inferior & $\mathrm{z}(-)$ & 180 & 0 & 0 & 0 & -1 \\
\hline 6 & Anterior- Left & $\mathrm{x}, \mathrm{y}$ & 90 & 45 & 0.707 & 0.707 & 0 \\
\hline $6^{*}$ & Anterior- Right & $\mathrm{x}, \mathrm{y}(-)$ & 90 & -45 & 0.707 & -0.707 & 0 \\
\hline 7 & Posterior- Left & $\mathrm{x}(-), \mathrm{y}$ & 90 & 135 & -0.707 & 0.707 & 0 \\
\hline $7^{*}$ & Posterior- Right & $\mathrm{x}(-), \mathrm{y}(-)$ & 90 & -135 & -0.707 & -0.707 & 0 \\
\hline 8 & Anterior-Superior & $\mathrm{x}, \mathrm{z}$ & 45 & 0 & 0.707 & 0 & 0.707 \\
\hline 9 & Posterior- Superior & $\mathrm{x}(-), \mathrm{z}$ & 45 & 180 & -0.707 & 0 & 0.707 \\
\hline 10 & Anterior- Inferior & $\mathrm{x}, \mathrm{z}(-)$ & 135 & 0 & 0.707 & 0 & -0.707 \\
\hline 11 & Posterior- Inferior & $\mathrm{x}(-), \mathrm{z}(-)$ & 135 & 180 & -0.707 & 0 & -0.707 \\
\hline 12 & Superior- Left & $\mathrm{y}, \mathrm{z}$ & 45 & 90 & 0 & 0.707 & 0.707 \\
\hline $12^{*}$ & Superior- Right & $\mathrm{y}(-), \mathrm{z}$ & 45 & -90 & 0 & -0.707 & 0.707 \\
\hline 13 & Inferior- Left & $\mathrm{y}, \mathrm{z}(-)$ & 135 & 90 & 0 & 0.707 & -0.707 \\
\hline $13^{*}$ & Inferior- Right & $\mathrm{y}(-), \mathrm{z}(-)$ & 135 & -90 & 0 & -0.707 & -0.707 \\
\hline 14 & Anterior- Left & $\mathrm{x}, \mathrm{y}$ & 90 & 22.5 & 0.923 & 0.382 & 0 \\
\hline $14^{*}$ & Anterior- Right & $\mathrm{x}, \mathrm{y}(-)$ & 90 & -22.5 & 0.923 & -0.382 & 0 \\
\hline 15 & Anterior- Left & $\mathrm{x}, \mathrm{y}$ & 90 & 67.5 & 0.382 & 0.923 & 0 \\
\hline $15^{*}$ & Anterior- Right & $\mathrm{x}, \mathrm{y}(-)$ & 90 & -67.5 & 0.382 & -0.923 & 0 \\
\hline 16 & Posterior- Left & $\mathrm{x}(-), \mathrm{y}$ & 90 & 112.5 & -0.382 & 0.923 & 0 \\
\hline $16^{*}$ & Posterior- Right & $\mathrm{x}(-), \mathrm{y}(-)$ & 90 & -112.5 & -0.382 & -0.923 & 0 \\
\hline 17 & Posterior- Left & $\mathrm{x}(-), \mathrm{y}$ & 90 & 157.5 & -0.923 & 0.382 & 0 \\
\hline $17^{*}$ & Posterior- Right & $\mathrm{x}(-), \mathrm{y}(-)$ & 90 & -157.5 & -0.923 & -0.382 & 0 \\
\hline 18 & Anterior-Superior & $\mathrm{x}, \mathrm{z}$ & 22.5 & 0 & 0.382 & 0 & 0.923 \\
\hline 19 & Anterior-Superior & $\mathrm{x}, \mathrm{z}$ & 67.5 & 0 & 0.923 & 0 & 0.382 \\
\hline 20 & Posterior- Superior & $\mathrm{x}(-), \mathrm{z}$ & 22.5 & 180 & -0.382 & 0 & 0.923 \\
\hline 21 & Posterior- Superior & $\mathrm{x}(-), \mathrm{z}$ & 67.5 & 180 & -0.923 & 0 & 0.382 \\
\hline 22 & Anterior- Inferior & $\mathrm{x}, \mathrm{z}(-)$ & 112.5 & 0 & 0.923 & 0 & -0.382 \\
\hline 23 & Anterior- Inferior & $\mathrm{x}, \mathrm{z}(-)$ & 157.5 & 0 & 0.382 & 0 & -0.923 \\
\hline 24 & Posterior- Inferior & $\mathrm{x}(-), \mathrm{z}(-)$ & 112.5 & 180 & -0.923 & 0 & -0.382 \\
\hline 25 & Posterior- Inferior & $\mathrm{x}(-), \mathrm{z}(-)$ & 157.5 & 180 & -0.382 & 0 & -0.923 \\
\hline 26 & Superior- Left & $\mathrm{y}, \mathrm{z}$ & 22.5 & 90 & 0 & 0.382 & 0.923 \\
\hline $26^{*}$ & Superior- Right & $\mathrm{y}(-), \mathrm{z}$ & 22.5 & -90 & 0 & -0.382 & 0.923 \\
\hline 27 & Superior- Left & $\mathrm{y}, \mathrm{z}$ & 67.5 & 90 & 0 & 0.923 & 0.382 \\
\hline $27^{*}$ & Superior- Right & $\mathrm{y}(-), \mathrm{z}$ & 67.5 & -90 & 0 & -0.923 & 0.382 \\
\hline 28 & Inferior- Left & $\mathrm{y}, \mathrm{z}(-)$ & 112.5 & 90 & 0 & 0.923 & -0.382 \\
\hline $28^{*}$ & Inferior- Right & $\mathrm{y}(-), \mathrm{z}(-)$ & 112.5 & -90 & 0 & -0.923 & -0.382 \\
\hline 29 & Inferior- Left & $\mathrm{y}, \mathrm{z}(-)$ & 157.5 & 90 & 0 & 0.382 & -0.923 \\
\hline $29^{*}$ & Inferior- Right & $\mathrm{y}(-), \mathrm{z}(-)$ & 157.5 & -90 & 0 & -0.382 & -0.923 \\
\hline 30 & Anterior- left-Superior & $\mathrm{x}, \mathrm{y}, \mathrm{z}$ & 45 & 45 & 0.577 & 0.577 & 0.577 \\
\hline $30^{*}$ & Anterior-Right -Superior & $\mathrm{x}, \mathrm{y}(-), \mathrm{z}$ & 45 & -45 & 0.577 & -0.577 & 0.577 \\
\hline 31 & Anterior- left- Inferior & $\mathrm{x}, \mathrm{y}, \mathrm{z}(-)$ & 135 & 45 & 0.577 & 0.577 & -0.577 \\
\hline $31^{*}$ & Anterior- Right -Inferior & $\mathrm{x}, \mathrm{y}(-), \mathrm{z}(-)$ & 135 & -45 & 0.577 & -0.577 & -0.577 \\
\hline 32 & Posterior - left-Superior & $\mathrm{x}(-), \mathrm{y}, \mathrm{z}$ & 45 & 135 & -0.577 & 0.577 & 0.577 \\
\hline $32^{*}$ & Posterior-Right -Superior & $\mathrm{x}(-), \mathrm{y}(-), \mathrm{z}$ & 45 & -135 & -0.577 & -0.577 & 0.577 \\
\hline 33 & Posterior- left- Inferior & $\mathrm{x}(-), \mathrm{y}, \mathrm{z}(-)$ & 135 & 135 & -0.577 & 0.577 & -0.577 \\
\hline $33^{*}$ & Posterior- Right-Inferior & $\mathrm{x}(-), \mathrm{y}(-), \mathrm{z}(-)$ & 135 & 135 & -0.577 & -0.577 & -0.577 \\
\hline
\end{tabular}

* Inputs that are symmetric relative to sagittal plane. 
due to the symmetry across the sagittal plane, resulting in 33 unique impact directions, as shown in Table 3 [27]. To simplify reporting the results, only 33 unique impact orientations were evaluated in studying the principal strain and shear stress in the brain. Calculations were made in order to indicate the principal strain and shear stress responses in brain tissues due to change in the impact directions. Finally, statistical analysis of the proposed head injury metrics was performed to predict brain reactions.

\section{Results}

\subsection{Effects of impact parameters on the brain Maximum Principal Strain (MPS)}

The brain response diagrams show that head impact orientation has a significant effect on the brain MPS. The MPS on the sagittal, frontal, and transverse planes occurred in the superior, superior, and posterior directions, respectively, while the minimum occurred in the inferior, inferior, and anterior directions, respectively. This finding shows that changing the impact direction in the sagittal, frontal, and transverse planes leads to changes by up to $5.08,2.89$, and 1.70 times in the MPS (Figures 4-6). Impact directions change the MPS since the head has multiple structures with varying material properties and geometries. In addition, the most sensitive orientation for changing the MPS is the inferior direction in the sagittal and frontal planes because of the high degree of relative brain/skull motions in this direction compared to others. A significantly high value of MPS was observed in the sagittal plane simulation compared to others (Figure 4). The values of MPS were lower in simulations with a pulse in the transverse plane than in others with no pulse (Figure 5). The MPS was obtained at 0.20 in the

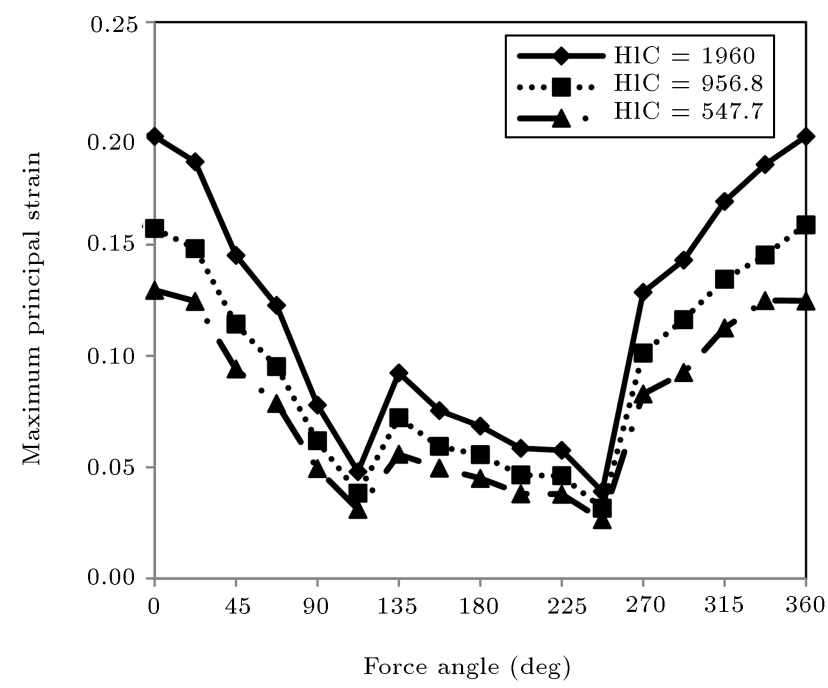

Figure 4. The effects of impact directions on maximum normal strain on the brain in the sagittal plane.

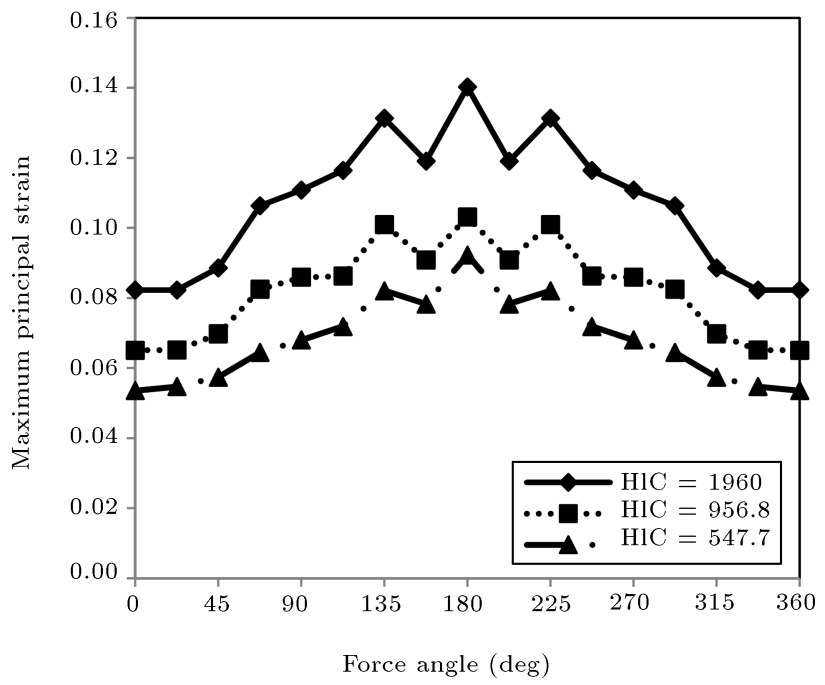

Figure 5. The effects of impact directions on maximum normal strain on the brain in the transverse plane.

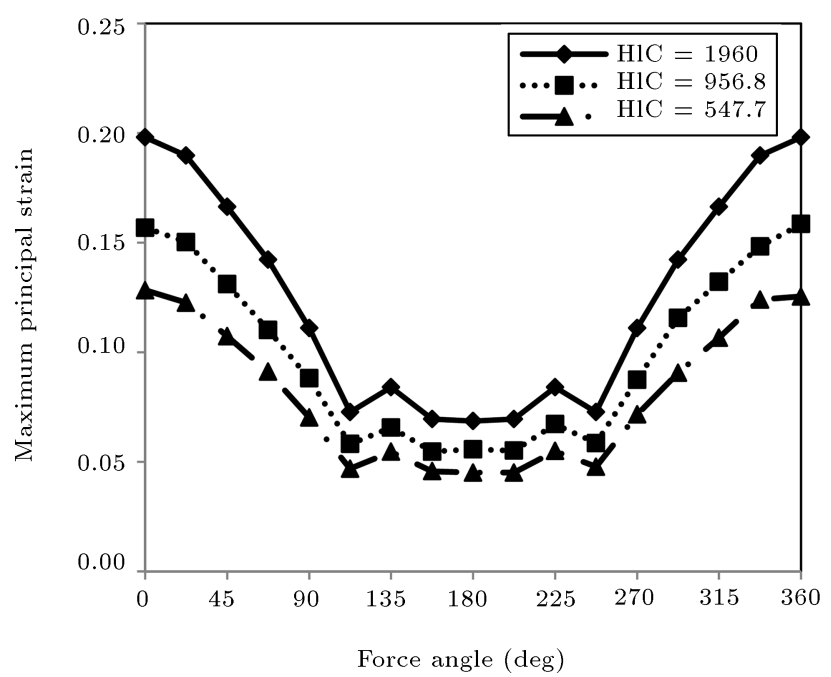

Figure 6. The effects of impact directions on maximum normal strain on the brain in the frontal plane.

sagittal plane, 0.20 in the frontal plane, and 0.14 in the transverse plane in the highest peak impact (R3) simulations (Figures 4-6). For the MPS, some similar trends were calculated in three input peaks by changing impact directions.

\subsection{Effects of impact parameters on the brain shear stress}

Diagrams for the maximum brain shear stress in different planes and orientations illustrate that impact direction has a considerable effect on the brain shear stress. The gap sizes between three input magnitudes for one direction of impact in Figure 7 show a non-linear relationship between shear stress and input peaks. Figures 7-9 demonstrate the maximum brain shear stress in the sagittal, frontal, and transverse planes occurring in the inferior, anterior, and inferior directions, while 


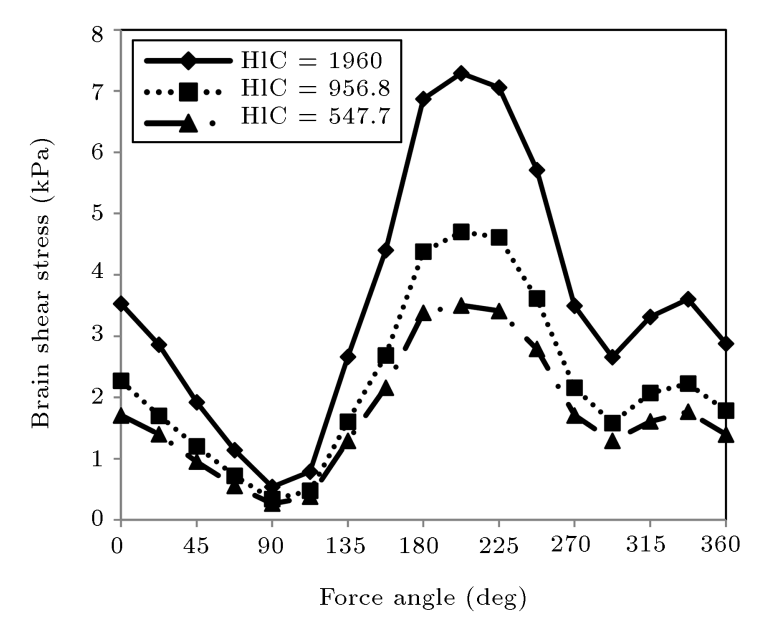

Figure 7. The effects of impact directions on maximum brain shear stress in the sagittal plane.

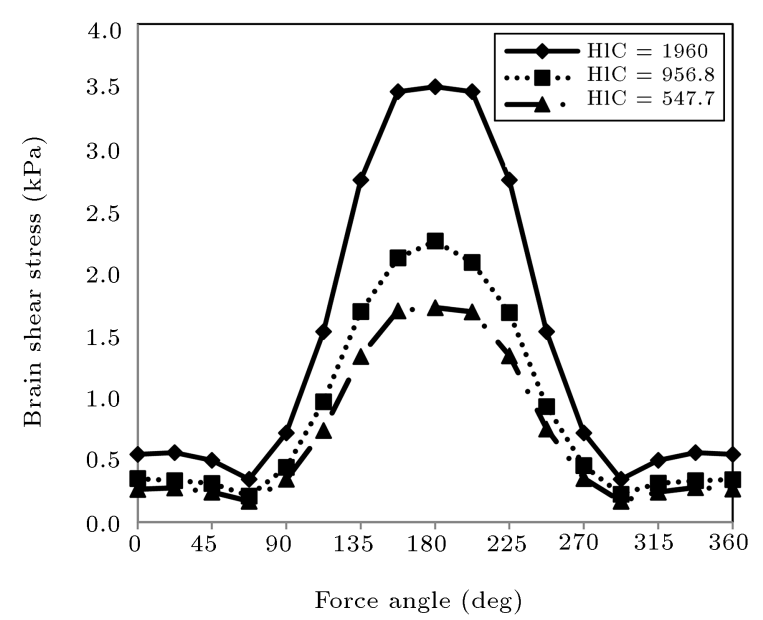

Figure 8. The effects of impact directions on maximum brain shear stress in the transverse plane.

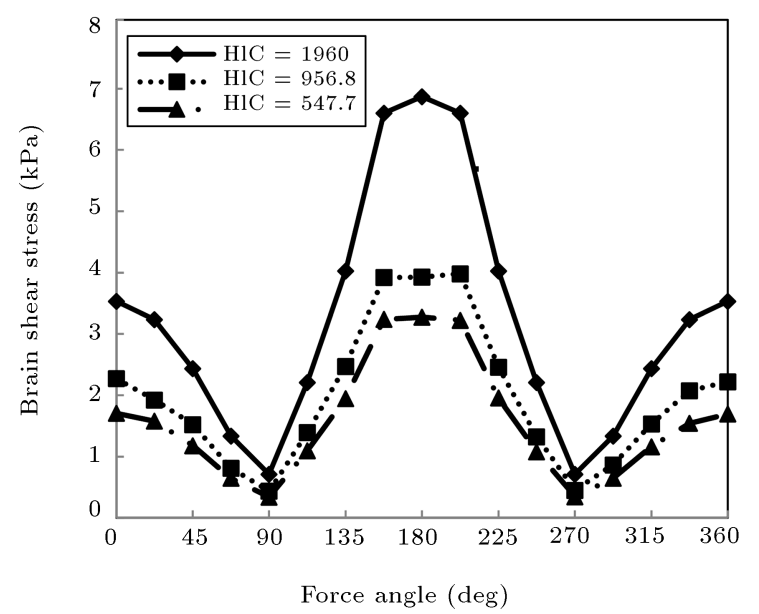

Figure 9. The effects of impact directions on maximum brain shear stress in the frontal plane.

the minimum occurs in the superior, right-left, and superior directions, respectively. Changing the impact orientations in the sagittal, frontal, and transverse planes led to changes by up to $13.44,9.06$, and 10.21 times in the brain shear stress. Furthermore, sagittal plane had the highest sensitivity to change in impact directions, which was observed when the direction was changed from superior to inferior. However, considerably greater values of maximum brain shear stress were seen in simulations with the transverse plane impacts than in those with transverse and frontal planes. These regional differences in shear stress with various impact directions are likely due to the geometry and specific anatomy in the head model. Considerably high values of shear stress were observed in simulations with sagittal plane impact compared to those with other planes (Figure 7 ). The shear stress values in the transverse plane impact simulations were lower than those in simulations with no pulse in the transverse plane (Figure 8). Maximum shear stress was obtained at $7.29 \mathrm{kPa}$ in the sagittal plane, $7.29 \mathrm{kPa}$ in the frontal plane, and $3.49 \mathrm{kPa}$ in the transverse plane in the highest peak impact (R3) simulations (Figures 7-9). For shear stress, similar trends were observed with three input magnitudes by changing impact orientations.

\subsection{Development of the new improved Head Injury Criteria (HIC)}

Brain injury risk, as calculated from brain MPS and shear stress, varied with impact directions. It increased with increase in the input peak for MPS and shear stress indices for any given impact directions. However, injury risk for MPS or shear stress varied with translational directions when the pulse magnitude was controlled (Table 4). The average injury risk in the highest magnitude (R1) simulations for the brain injury index was $2.77 \mathrm{kPa}$ for the shear stress and 0.11 for MPS. Maximum injury risk in all simulations at the highest input peak (R1) was $7.29 \mathrm{kPa}$ for brain maximum shear stress and 0.20 for brain MPS injuries. The lowest variation was observed in MPS risk at magnitude R3 with an injury risk differential of 0.10 . On the contrary, the highest differences were seen in shear stress risk at magnitude R1 with an injury risk differential of $6.95 \mathrm{kPa}$. Variation in injury risk due to the impact directions increased with an increase in the input magnitude. In addition, variations of shear stress due to change in the impact directions were higher than brain MPS variations.

Non-linear relationship was observed between HIC values and input magnitudes for gap sizes of three peak pulses in each impact direction, as shown in Table 2. The results of the head impact FEM simulations showed that head impact directions could have a significant effect on the brain reactions. Moreover, they revealed that TBI risk could increase by changing the impact magnitudes and HIC levels. Thus, effective factors were evaluated based on the findings for brain 
Table 4. Summary of brain injury indices grouped by input peak.

\begin{tabular}{ccccccc}
\hline Injury index & Input magnitude & Ave & SD & Min & Max & Differential \\
\hline \multirow{3}{*}{ Shear stress $(\mathrm{kPa})$} & $\mathrm{R} 1$ & 2.77 & 2.02 & 0.34 & 7.29 & 6.95 \\
& $\mathrm{R} 2$ & 1.72 & 1.25 & 0.21 & 4.70 & 4.49 \\
& $\mathrm{R} 3$ & 1.35 & 0.98 & 0.17 & 3.50 & 3.34 \\
& & & & & & \\
MPS & $\mathrm{R} 1$ & 0.11 & 0.04 & 0.04 & 0.20 & 0.16 \\
& $\mathrm{R} 2$ & 0.09 & 0.03 & 0.03 & 0.16 & 0.13 \\
& $\mathrm{R} 3$ & 0.07 & 0.03 & 0.03 & 0.13 & 0.10 \\
\hline
\end{tabular}

Table 5. Coefficients of determination $\left(\mathrm{R}_{2}\right)$ and $p$-values for the brain reactions versus the developed brain injury.

\begin{tabular}{ccc}
\hline HIC & Correlation coefficient & $\boldsymbol{p}$-value \\
\hline MPSC & 0.85 & $<0.001$ \\
SSC & 0.89 & $<0.001$ \\
\hline
\end{tabular}

reactions (maximum brain shear stress and normal strain) by performing statistical analyses of three different magnitudes of linear acceleration applying about 50 different orientations, resulting in 150 simulations (Table 3 ). Then, the simulation results were studied and new head injury indices were obtained through Eqs. (4) and (5) using the Design-Expert software. The indices were shear stress criterion (Eq. (4)) and MPS criterion (Eq. (5)), predicting shear stress and MPS, respectively. In these equations, $A$ and $B$ are defined as $\cos \varphi$ and $\cos \theta$, respectively. Results from regression analysis showed high correlation between FEM simulation results and the proposed brain injury indices (Table 5). The equations predicted brain responses for head FEM with the material properties indicated in Table 5:

$$
\begin{aligned}
& S S C=\text { Shear Stress Criteria }= \\
& \frac{\left(0.0129 H I C^{0.57}\right) \times 100}{7.5} \times[1.11-1.64 A-1.36 B \\
& \left.+0.67 A B+4.05 A^{2}+0.73 \times B^{2}\right]
\end{aligned}
$$

$M P S C=$ Maximum Principal Strain Criteria $=$

$$
\begin{aligned}
& \frac{\left(0.076 H I C^{0.03}\right) \times 100}{0.25} \times[0.11+0.078 A-0.029 B \\
& \left.+0.025 A^{2}+0.029 A^{2} B-0.016 A^{3}+0.011 B^{3}\right] .
\end{aligned}
$$

\section{Discussion}

Different layers and material properties composing head geometry may affect the brain response values during impacts with different loading directions. The present research indicates that the highest brain stress and pressure do not occur in specific head impact directions. Most of the injury criteria such as HIC [18] and BRIC [20] predict TBI injury risk only with peak accelerations, not through applied pulses in different directions. Therefore, they calculate the risk of injury for inputs with the same acceleration profiles in the same way regardless of impact directions. This study used FEM simulations to investigate the effects of impact orientations and peaks for TBI injury risk using FEM head simulations. The results clearly showed that impact directions had significant effects on the brain reactions and head injury risk. Therefore, new brain injury indices should be employed to take impact directions into consideration. New HIC were developed to predict intracranial responses and TBI risk considering impact directions, magnitudes, and time. While the previous HIC could not determine how inputs affected brain reactions and they were only capable of assessing TBI risk, the newly developed HIC, including MPSC and SSC, could identify the MPS and shear stress in different head impact incidents. The findings of the previous studies were consistent with the results of the present research, showing that motion in the sagittal direction would exert stress and strain on the brain, leading to high TBI risk [35]. The stress and strain are caused by a high degree of relative brain/skull motions. This is why TBI risk is lower with impacts on the head sides and, in general, higher pulse magnitudes are required in such cases.

\section{Conclusion}

The relationship between brain reactions and orientations of head impacts was investigated through a 3D head Finite Element Model (FEM) with Maximum Principal Strain (MPS) and shear stress metrics. Results indicated that impact directions should be considered in order to determine the head injury risk. Moreover, they showed that the stress and strain imposed on the brain in sagittal and frontal planes were higher than those in the transverse planes. Also, analysis of head linear accelerations in different directions showed that Head Injury Criteria (HIC) should be developed for predicting Traumatic Brain Injury (TBI) risk. Hence, new brain injury criteria were proposed using statistical analysis and head FEM to predict the brain reactions. Maximum Principal Strain Criteria 
(MPSC) and shear stress criteria (SSC) had correlation coefficients of 0.85 and 0.89 with finite element results, respectively. The findings of this research can be used to better understand the relationship between head impact orientations and the stress and strain imposed on the brain. Moreover, protective equipment and safety systems may be improved to protect humans against head impact events using the results of this research.

\section{Acknowledgments}

This research received no specific grant from any funding agency in the public, commercial, or not-forprofit sector.

\section{References}

1. Faul, M., Xu, L., Wald, M.M., and Coronado, V.G. "Traumatic brain injury in the United States", Atlanta, GA Natl. Cent. Inj. Prev. Control. Centers Dis. Control Prev. (2010).

2. Sosin, D.M., Sniezek, J.E., and Thurman, D.J. "Incidence of mild and moderate brain injury in the United States, 1991", Brain Inj., 10(1), pp. 47-54 (1996).

3. Styrke, J., Stalnacke, B.-M., Sojka, P., and Björnstig, U. "Traumatic brain injuries in a well-defined population: epidemiological aspects and severity", $J$. Neurotrauma, 24(9), pp. 1425-1436 (2007).

4. Mccuen, E., Svaldi, D., Breedlove, K., Kraz, N., Cummiskey, B., Breedlove, E.L., Traver, J., Desmond, K.F., Hannemann, R.E., Zanath, E., Guerra, A., Leverenz, L., Talavage, T.M., and Nauman, E.A. "Collegiate women $\hat{a} \in^{\mathrm{TM}} \mathrm{s}$ soccer players suffer greater cumulative head impacts than their high school counterparts", $J$. Biomech., 48(13), pp. 1-4 (2015).

5. Greenwald, R.M., Gwin, J.T., Chu, J.J., and Crisco, J.J. "Head impact severity measures for evaluating mild traumatic brain injury risk exposure", Neurosurgery, 62(4), p. 789 (2008).

6. Hajiaghamemar, M., Seidi, M., Ferguson, J.R., and Caccese, V. "Measurement of head impact due to standing fall in adults using anthropomorphic test dummies", Ann. Biomed. Eng., 43(9), pp. 2143-2152 (2015).

7. Breedlove, K.M., Breedlove, E.L., Bowman, T.G., and Nauman, E.A. "Impact attenuation capabilities of football and lacrosse helmets", J. Biomech., 49(13), pp. 2838-2844 (2016).

8. Weaver, A.A., Danelson, K.A., and Stitzel, J.D. "Modeling brain injury response for rotational velocities of varying directions and magnitudes", Ann. Biomed. Eng., 40(9), pp. 2005-2018 (2012).

9. Milne, G., Deck, C., Bourdet, N., Carreira, R.P., Allinne, Q., Gallego, A., and Willinger, R. "Bicycle helmet modelling and validation under linear and tangential impacts", Int. J. Crashworthiness, 19(4), pp. 323-333 (2014).
10. Patton, D.A., McIntosh, A.S., and Kleiven, S. "The biomechanical determinants of concussion: finite element simulations to investigate tissue-level predictors of injury during sporting impacts to the unprotected head", J. Appl. Biomech., 31(4), pp. 264-268 (2015).

11. Rowson, S., Beckwith, J.G., Chu, J.J., Leonard, D.S., Greenwald, R.M., and Duma, S.M. "A six degree of freedom head acceleration measurement device for use in football", J. Appl. Biomech, 27(1), pp. 8-14 (2011).

12. Lintern, T.O., Gamage, N.T.P., Bloomfield, F.H., Kelly, P., Finch, M.C., Taberner, A.J., Nash, M.P., and Nielsen, P.M.F. "Head kinematics during shaking associated with abusive head trauma", J. Biomech., 48(12), pp. 3123-3127 (2015).

13. Crisco, J.J., Costa, L., Rich, R., Schwartz, J.B., and Wilcox, B. "Surrogate headform accelerations associated with stick checks in girls' lacrosse", J. Appl. Biomech., 31(2), pp. 122-127 (2015).

14. Gabler, L.F., Crandall, J.R., and Panzer, M.B. "Assessment of kinematic brain injury metrics for predicting strain responses in diverse automotive impact conditions", Ann. Biomed. Eng., 44(12), pp. 37053718 (2016).

15. Post, A., Hoshizaki, T.B., Gilchrist, M.D., Brien, S., Cusimano, M.D., and Marshall, S. "The influence of acceleration loading curve characteristics on traumatic brain injury", J. Biomech., 47(5), pp. 1074-1081 (2014).

16. Kuo, C., Wu, L.C., Hammoor, B.T., Luck, J.F., Cutcliffe, H.C., Lynall, R.C., Kait, J.R., Campbell, K.R., Mihalik, J.P., Bass, C.R., and Camarillo, D.B. "Effect of the mandible on mouthguard measurements of head kinematics", J. Biomech., 49(9), pp. 18451853 (2016).

17. Butz, R.C., Knowles, B.M., Newman, J.A., and Dennison, C.R. "Effects of external helmet accessories on biomechanical measures of head injury risk: An ATD study using the HYBRIDIII headform", J. Biomech., 48(14), pp. 3816-3824 (2015).

18. Versace, J., A Review of the Severity Index, SAE Technical Paper (1971).

19. Gadd, C.W., Use of a Weighted-Impulse Criterion for Estimating Injury Hazard, SAE Technical Paper (1966).

20. Takhounts, E.G., Hasija, V., Ridella, S.A., Rowson, S., and Duma, S.M. "Kinematic rotational brain injury criterion (BRIC)", Proc. 22nd Enhanc. Saf. Veh. Conf. Pap. (2011).

21. Kimpara, H. and Iwamoto, M. "Mild traumatic brain injury predictors based on angular accelerations during impacts", Ann. Biomed. Eng., 40(1), pp. 114-126 (2012).

22. Wright, R.M., A Computational Model for Traumatic Brain Injury Based on an Axonal Injury Criterion, The Johns Hopkins University (2012). 
23. Rowson, S., Duma, S.M., Beckwith, J.G., Chu, J.J., Greenwald, R.M., Crisco, J.J., Brolinson, P.G., Duhaime, A.-C., McAllister, T.W., and Maerlender, A.C. "Rotational head kinematics in football impacts: an injury risk function for concussion", Ann. Biomed. Eng., 40(1), pp. 1-13 (2012).

24. Dikmen, S.S., Corrigan, J.D., Levin, H.S., Machamer, J., Stiers, W., and Weisskopf, M.G. "Cognitive outcome following traumatic brain injury", J. Head Trauma Rehabil., 24(6), pp. 430-438 (2009).

25. Amen, D.G., Wu, J.C., Taylor, D., and Willeumier, K. "Reversing brain damage in former NFL players: implications for traumatic brain injury and substance abuse rehabilitation", J. Psychoactive Drugs, 43(1), pp. 1-5 (2011).

26. Afshari, J., Haghpanahi, M., Kalantarinejad, R., and Rouboa, A. "Biomechanical investigation of astronaut's seat geometry to reduce neck and head injuries while landing impact", Int. J. Crashworthiness, 23(4), pp. 1-11 (2017).

27. Afshari, J., Haghpanahi, M., and Kalantarinejad, R. "Developing new brain injury criteria for predicting the intracranial response by calculating von Mises stress, coup pressure and contrecoup pressure", J. Brazilian Soc. Mech. Sci. Eng., pp. 1-13 (2017).

28. Gennarelli, T.A., Thibault, L.E., Tomei, G., Wiser, R., Graham, D., and Adams, J. "Directional dependence of axonal brain injury due to centroidal and non-centroidal acceleration", SAE Tech. Pap., 872197 (1987).

29. Kleiven, S. "Influence of impact direction on the human head in prediction of subdural hematoma", $J$. Neurotrauma, 20(4), pp. 365-379 (2003).

30. Huang, H.-M., Lee, M.-C., Chiu, W.-T., Chen, C.T., and Lee, S.-Y. "Three-dimensional finite element analysis of subdural hematoma", J. Trauma Acute Care Surg., 47(3), pp. 538-544 (1999).

31. Ji, S. and Zhao, W. "A Pre-computed brain response atlas for instantaneous strain estimation in contact sports", Ann. Biomed. Eng., 43(8), pp. 1877-1895 (2015).

32. Pasha Zanoosi, A.A., Mallakzadeh, M., and Kalantarinejad, R. "Optimal frame geometry of spacecraft seat based on multi-body dynamics modelling", Acta Astronaut., 115, pp. 58-70 (2015).

33. Ghaffari, M., Zoghi, M., Rostami, M., and Abolfathi, N. "Fluid structure interaction of traumatic brain injury: effects of material properties on SAS trabeculae", Int. J. Mod. Eng., 14(2), pp. 54-62 (2014).

34. Hernandez, F., Wu, L.C., Yip, M.C., Laksari, K., Hoffman, A.R., Lopez, J.R., Grant, G.A., Kleiven, S., and Camarillo, D.B. "Six degree-of-freedom measurements of human mild traumatic brain injury", Ann. Biomed. Eng., 43(8), pp. 1918-1934 (2015).

35. Post, A., Hoshizaki, T.B., Gilchrist, M.D., Brien, S., Cusimano, M., and Marshall, S. "Traumatic brain injuries: the influence of the direction of impact", Neurosurgery, 76(1), pp. 81-91 (2015).
36. Takhounts, E.G., Craig, M.J., Moorhouse, K., McFadden, J., and Hasija, V. "Development of brain injury criteria (BrIC)", Stapp Car Crash J., 57, p. 243 (2013).

37. Gabler, L., Crandall, J., and Panzer, M. "Investigating brain injury tolerance in the sagittal plane using a finite element model of the human head", Int. J. Automot., 7(1), pp. 37-43 (2016).

38. Eslaminejad, A., Hosseini Farid, M., Ziejewski, M., and Karami, G. "Brain tissue constitutive material models and the finite element analysis of blast-induced traumatic brain injury", Sci. Iran., 25(6), pp. 31413150 (2018).

39. Saboori, P. and Sadegh, A. "Material modeling of the head's subarachnoid space", Sci. Iran., 18(6), pp. 1492-1499 (2011).

40. Horgan, T.J. and Gilchrist, M.D. "The creation of three-dimensional finite element models for simulating head impact biomechanics", Int. J. Crashworthiness, 8(4), pp. 353-366 (2003).

41. Zhou, C., Khalil, T.B., and King, A.I. "Viscoelastic response of the human brain to sagittal and lateral rotational acceleration by finite element analysis", International IRCOBI Conference on the Biomechanics of Impacts, Dublin (1997).

42. Nahum, A.M., Smith, R., and Ward, C.C. "Intracranial pressure dynamics during head impact", Stapp Car Crash Conference (1977).

43. Trosseille, X., Tarriére, C., Lavaste, F., Guillon, F., and Domont, A. "Development of a F.E.M. of the human head according to a specific test protocol", 36th Stapp Car Crash Conference (1992).

44. Post, A., Hoshizaki, T.B., Gilchrist, M.D., Brien, S., Cusimano, M., and Marshall, S. "Traumatic brain injuries: the influence of the direction of impact", Neurosurgery, 76(1), pp. 81-91 (2015).

45. Kleiven, S. "Predictors for traumatic brain injuries evaluated through accident reconstructions", Stapp Car Crash J., 51, p. 81 (2007).

46. Mao, H., Zhang, L., Jiang, B., Genthikatti, V.V., Jin, X., Zhu, F., Makwana, R., Gill, A., Jandir, G., Singh, A., and Yang, K.H. "Development of a finite element human head model partially validated with thirty five experimental cases", J. Biomech. Eng., 135, p. 111002 (2013).

47. Peng, Y., Deck, C., Yang, J., Otte, D., and Willinger, R. "A study of adult pedestrian head impact conditions and injury risks in passenger car collisions based on real-world accident data", Traffic Inj. Prev., 14(6), pp. 639-46 (2013).

\section{Biographies}

Javad Afshari received his BS and MS degrees in Mechanical Engineering from Bu-Ali Sina University, Hamedan, Iran, in 2007 and 2012, respectively, and $\mathrm{PhD}$ degree in the same field of study from Iran 
University of Science and Technology, Tehran, Iran, in 2017. His research interests include head injury, robot path planning, and mechanical engineering.

Mohammad Haghpanahi is a Professor of Mechanical and Biomechanical Engineering in the School of Mechanical Engineering at Iran University of Science and Technology, Tehran. His research interests are orthopedic biomechanics, sports biomechanics, vibration and modal analysis of mechanical systems, and finite element analysis of stress in systems.

Reza Kalantarinejad is an entrepreneur in the field of converging technologies. He is an Associate Professor in the Aerospace Research Inst. He conducted his $\mathrm{PhD}$ dissertation on designing a nano-biosensor using modern quantum transport approaches. He is the founder of SHEZAN and HAMGARA corporations and co-founder of SAFE and ISMS start-up companies. He has several patents and journal papers in the field of nanotechnology, biotechnology in particular.

Abel Rouboa is a Professor in the Engineering Department of the University of Trás-os-Montes e Alto Douro, Portugal. He is the lead of the CFD research group with five $\mathrm{PhD}$ graduates, three $\mathrm{PhD}$ candidates, and five MSc students and PI of biomechanics projects linked to sports research groups of UTAD, UPorto, and IST. He is the Head of several RD projects on applied and renewable energy financed by national and International foundations. 